\title{
The Drug Development Based on Pathogenetic Research in Alzheimer's Disease
}

\author{
Xiaoqian Lin, Qingzhu Zhang \\ Pharmacological Institute of New Drugs, School of Pharmacy, Shandong University, Ji'nan, China \\ Email: zhangqzh@sdu.edu.cn, linxqsdu@163.com
}

Received 25 February 2014; revised 1 April 2014; accepted 10 April 2014

Copyright (C) 2014 by authors and Scientific Research Publishing Inc.

This work is licensed under the Creative Commons Attribution International License (CC BY). http://creativecommons.org/licenses/by/4.0/ c) (i) Open Access

\begin{abstract}
Neuropathologically, Alzheimer's disease is characterized by the presence of extracellular deposits of amyloid- $\beta$ peptides, intracellular neurofibrillary tangles and atrophy of the basal forebrain cholinergic neurons. The research of pathogenesis of Alzheimer's disease inspirits potential clinical drugs for treatment. To block the progression of the disease, drugs under development have to interfere with the pathogenic steps responsible for the clinical symptoms, including cholinergic deficit, calcium dysregulation, inflammation and oxidative damage, and the deposition of amyloid$\beta$ plaques and of neurofibrillary tangles. In this review, the pertinent literature about drugs targeted on relieving symptoms above is reviewed. We aim to discuss possible research priorities in the future.
\end{abstract}

\section{Keywords}

Alzheimer's Disease, A $\beta$, Protein Tau, ULMWH, MT-Stabilizing Agents

\section{Introduction}

Alzheimer's disease (AD) is described as one of the most common neurodegenerative disorders, with a prevalence of 5 percent after sixty-five years of age, increasing to almost 30 percent in people over age eighty-five [1]. The clinical symptoms of AD include loss of memory, progressive cognitive impairment, various behavioral disturbances and neurological disorders. Typically, AD start with mild memory deficits, then gradually progress to severe dementia and stupor. Generally speaking, about nine years after clinical diagnosis, the AD patients may face to death caused by respiratory complications [2]. Neuropathologically, AD is characterized by senile plaques (SP) composed by amyloid- $\beta$ peptides (A $\beta$ ), neurofibrillary tangles (NFTs) generated by hyper-phos- 
phorylated forms of protein tau [3] and degeneration or atrophy of the basal forebrain cholinergic neurons.

APP is overexpressed in AD [4]. After the cleavage of APP by two proteases, denoted as $\beta$-secretase (BACE1) and $\gamma$-secretase, the sequential action will aggregates into toxic $\mathrm{A} \beta$. The two major subtypes are $\mathrm{A} \beta_{1-40}$ and $\mathrm{A} \beta_{1-42}$. The shorter one comes from the cutting of typical APP in endoplasmic reticulum, while the longer one is formed across the Golgi network. Compared with each other, $\mathrm{A} \beta_{1-40}$ is more common, but $\mathrm{A} \beta_{1-42}$ is even more relevant to the disease. Tau is a component of microtubules; it stabilizes growing axons and is necessary for neuritis [4]. In $\mathrm{AD}$, tau is abnormally hyperphosphorylated and forms insoluble fibrils, which contribute to the earliest cytoskeletal changes in NFTs formation. This abnormal spiral structure interfere the normal function of neurons, ultimately leading to neuronal cell death. Cholinesterase is the key enzyme in biological nerve conduction. In the cholinergic synaptic cleft, it degrades acetylcholine, induces the termination of excitability role of the neurotransmitter on postsynaptic membrane, which ensures normal convery of nerve signals in vivo. Acetylcholinesterase catalyzes the cleavage reaction of acetylcholine, resulting in the lack of acetylcholine, thus interfere nerve signal transmission.

Alzheimer's disease pathology changes major involve cholinergic nerve pathways from frontal base to the cerebral cortex and hippocampus. As we all known, these pathways are associated with attention, learning ability, memory and other cognitive processes. The loss of basal forebrain cholinergic cells in AD patients leads to reduction of synaptic availability of acetylcholine. So, AD patients always suffer the cognitive impairment.

Scientists have been working on the pathophysiological processes of Alzheimer's disease for more than a century. A large number of theories have been discovered to explain what is happening in the brain of AD patients. For example, $\mathrm{A} \beta$ causes calcium dysregulation and oxidative stress in central nervous system cells, inflammatory changes can be observed in the brain, even diabetes and insulin-resistance may have connection with AD through GSK3 $\beta$. Nevertheless, there is a long way to go before we discover the exactly and comprehensive functions of $\mathrm{A} \beta$ and tau in the process of $\mathrm{AD}$. In other hand, the significantly effective drugs for $\mathrm{AD}$ clinical treatment are less than enough. In this article, we focus on the molecular and cellular alterations involved in neuronal dysfunctions caused by $\mathrm{A} \beta$ and tau in $\mathrm{AD}$. More importantly, the drug development based on pathogenetic research in $\mathrm{AD}$, and possible research priorities in the future will be mentioned.

\section{Cholinergic Drugs}

Neurochemical research shows that the brain in $\mathrm{AD}$ patients have obvious shortage of central cholinergic neurotransmitter, causing loss of memory, directional force, behavior and personality change as a result. Enhancing cholinergic effects is an important way for the treatment of AD. Current research focuses on acetylcholinesterase inhibitors (AChEI), which can increase ACh concentration in the synaptic cleft by reducing its degradation, thus improve the central activity of choline. It is by far the most commonly used and is considered to be one of the most promising drug treatments of AD. The second generation of AChEI is widely applied in clinical treatment, that is Donepezil hydrochloride (aricept) [5], Rivastigmine Tartrate (exelon) [6], Galantamine and Huperzine A.

Donepezil hydrochloride is a highly selective AChEI. It is approved for use in mild-to-moderate AD patients [7] [8]. It has shown some benefit in slowing hippocampal atrophy and protecting nerve cells. Rivastigmine Tartrate has easy BBB permeability and is approved for mild-to-moderate AD [9]. Rivastigmine Tartrate can selectively enhance the effect of acetylcholine in cerebral cortex and hippocampus. Furthermore, cholinesterase inhibitors can slow down the the formation of the amyloid precursor protein (APP) fragment. After combining with its target enzyme into covalent compounds, Rivastigmine Tartrate causes a temporary loss of activity of the enzyme. Galantamine has allosteric nicotinic receptor modulation properties. Galantamine may increase ACh release by regulating brain external nicotinic acid receptor. Research showed that galantamine may be safe for the treatment of elderly patients with severe $\mathrm{AD}$, which improves cognitive function in patients. However, everyday life parameters change is not obvious. Another ChEI, Huperzine A, is considered to be one of the treatment for memory disorders [10]. However, for its lacking of proprietary patent for the treatment of AD, it is considered as a nutraceutical supplement in the US. Clinical and preclinical toxicities are to be established in the future.

$\mathrm{AD}$ is a multifactorial disease, so the innovative model is to achieve the goal of "one molecule, multiple targets”. Ideally, hybrids can provide parent compounds more potency such as BBB permeability, additional receptors or epitopes [11]. Human studies are planned. 


\section{Calcium Regulation as a Therapeutic Approach for AD}

There is considerable evidence that $\mathrm{A} \beta$ induces calcium dysregulation in neuron. Sequential cleavages of APP by secretases generate $\operatorname{sAPP} \alpha, \mathrm{A} \beta$ and AICD. Intracellular APP domain (AICD) can modify nuclear gene transcription and further more perturb $\mathrm{Ca}^{2+}$ homeostasis. On the other hand, $\operatorname{sAPP} \alpha$, generated from APP by $\alpha$-secretase, is normally produced to active $\mathrm{K}^{+}$channels, thereby hyperpolarizing the membrane and reducing $\mathrm{Ca}^{2+}$ influx [12]. The production of sAPP $\alpha$ plays a protecting role in neurons; however, amyloidgenic processing may prevent this program. $\mathrm{A} \beta$ oligomers enhance calcium ion influx by $\mathrm{Ca}^{2+}$-permeable channels, which can be facilitated by binding to phosphatidylserine (PtdS). Cell-surface exposure of PtdS is usually indicative of apoptotic cells. Mitochondrial, the energy supply station of cells, once effected by $\mathrm{A} \beta$, will induce superoxide anion radical $\left(\mathrm{O} 2 \bullet^{-}\right)$production, $\mathrm{Ca}^{2+}$ overload, and decreased ATP production. In this condition, PtdS will flip from the inner portion to the cell surface of the plasma membrane. In turn, neurons with lower ATP level are particularly susceptible to $\mathrm{A} \beta$ toxicity [13]. $\mathrm{A} \beta$ can also generate hydroxyl radical $(\mathrm{OH})$ in the presence of $\mathrm{Fe}^{2+}$ and $^{+\mathrm{Cu}^{+}}[14]$ [15]. As a result, the function of ATPases dependent ion channels ( $\mathrm{Na}^{+}$and $\mathrm{Ca}^{2+}$ pumps) can be impaired by toxic aldehydes generated by membrane lipid peroxidation (LP). Therefore, the membrane becomes depolarized and toxic amounts of $\mathrm{Ca}^{2+}$ flux into the cytoplasm through the open channels, glutamate receptor channels (N-methyl$\mathrm{D}$-aspartate receptor, NMDAR) and voltage-dependent $\mathrm{Ca}^{2+}$ channels (VDCC) open. Inside the neurons, Presenilins (PS) functions as an endoplasmic reticulum (ER) $\mathrm{Ca}^{2+}$ leak channel. In familial Alzheimer's disease, PS mutations cause excessive accumulation of $\mathrm{Ca}^{2+}$ and then enhance $\mathrm{Ca}^{2+}$ release by inositol $1,4,5$-trisphosphate receptors $\left(\mathrm{IP}_{3} \mathrm{R}\right)$ channels and ryanodine receptor (RyR). $\mathrm{A} \beta$ can also block the response of nicotinic acetylcholine receptors (nAChRs) and induces sustained $\mathrm{Ca}^{2+}$ levels increases in presynaptic through $\mathrm{IP}_{3}$ [16] (Figure 1).

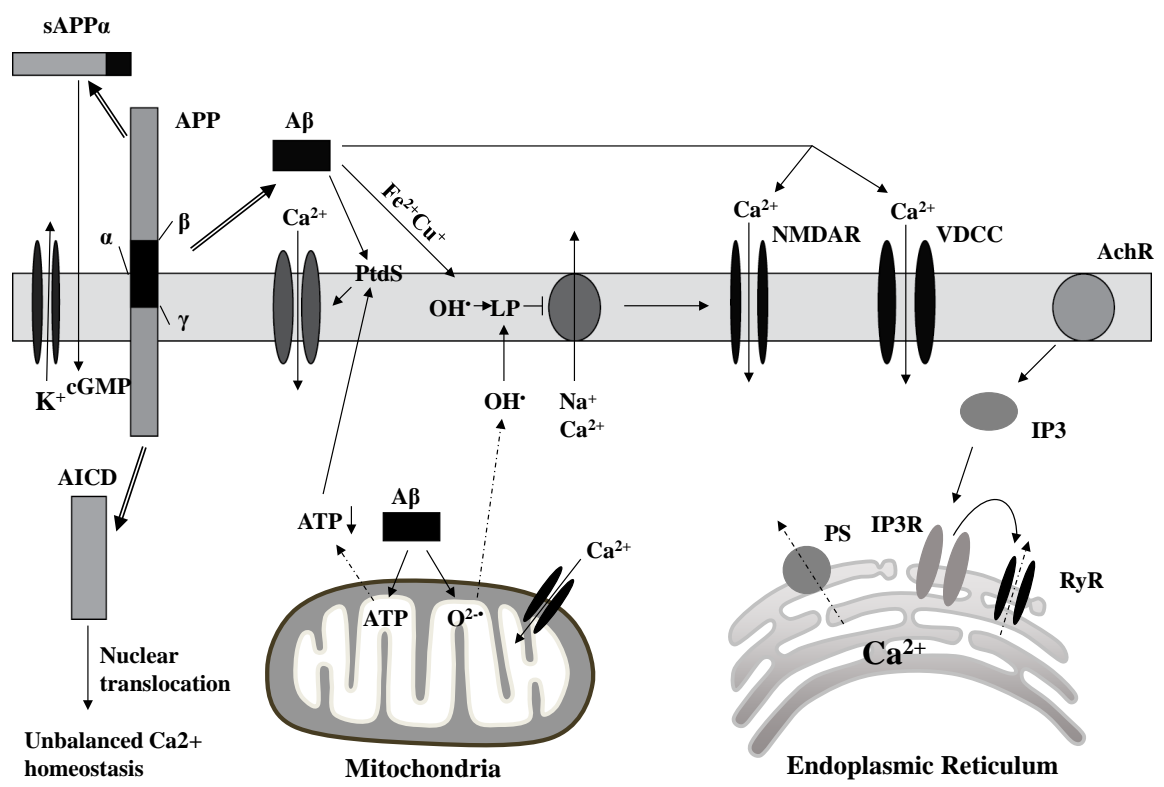

Figure 1. Molecular and cellular alterations involved in neuronal dysfunction in AD. The amyloid- $\beta$ precursor protein (APP) can be cleaved by $\beta$-secretase and $\gamma$-secretase, resulting in the liberation of $\operatorname{sAPP} \alpha$, the amyloid- $\beta$ peptitde $(\mathrm{A} \beta)$ and intracellular APP domain (AICD). AICD can translocate to the nucleus and perturb $\mathrm{Ca}^{2+}$ homeostasis. sAPP $\alpha$ may active $\mathrm{K}^{+}$channels. $\mathrm{A} \beta$ oligomers enhance calcium ion influx into the cell by the formation of $\mathrm{Ca}^{2+}$-permeable channels. A $\beta$ will also induce superoxide anion radical $\left(\mathrm{O}_{2}{ }^{-}\right)$production, $\mathrm{Ca}^{2+}$ overload, and decreased ATP production in mitochondrial. A $\beta$ can also interact with $\mathrm{Fe}^{2+}$ and $\mathrm{Cu}^{+}$to generate hydrogen peroxide and hydroxyl radical $(\mathrm{OH})$. As a result, the function of $\mathrm{Na}^{+}$and $\mathrm{Ca}^{2+}$ pumps can be impaired by toxic aldehydes generated by membrane lipid peroxidation (LP), resulting the $\mathrm{Ca}^{2+}$ flux through N-methyl-D-aspartate receptor (NMDAR) and voltage-dependent $\mathrm{Ca}^{2+}$ channels (VDCC). In familial Alzheimer's disease, Presenilins (PS) mutations cause excessive accumulation of $\mathrm{Ca}^{2+}$ in the endoplasmic reticulum (ER) and then enhance $\mathrm{Ca}^{2+}$ release through inositol 1,4,5-trisphosphate receptors $\left(\mathrm{IP}_{3} \mathrm{R}\right)$ channels and ryanodine receptor (RyR). A $\beta$ can also induce sustained nAChR-mediated increases in presynaptic $\mathrm{Ca}^{2+}$ levels through $\mathrm{IP}_{3}$. 
Inspired by the above theory, methods to stabilize neural intracellular calcium homeostasis may be one of the treatments for AD. So far, a variety of drugs have therapeutic potential in vivo or in vitro experiments.

Since excessive activation of glutamate system causes excitotoxic neuronal death, NMDA open channel blocker, can antagonize glutamate excitotoxicity. Memantine, which belongs to NMDA receptor antagonist, is different from the cholinesterase inhibitor. It is the first and only drug that is approved for treatment of moderate to severe AD. Clinical studies have demonstrated that it benefits in cognitive and behavioral outcomes in patients, either as monotherapy or in combination with donepezil [17]. It also shows good effect to main types of dementia: Alzheimer's dementia, vascular dementia and AIDS dementia, which indicate that it has an advangtage over other kinds of AD drugs on the market. Animal experiments showed that Nimodipine, an L-type VGCC inhibitor, plays a role as calcium antagonist. It decreases the intracellular calcium ion concentration, promotes the regeneration of injured neurons, enhance the plasticity of the aging central nervous system. In the clinical treatment, Nimodipine has obvious curative effect on memory impairment due to AD [18]. Recently, nimodipine was reported to selectively stimulate secretion of $\mathrm{A} \beta_{1-42}$ slightly [19]. But the exact mechanism has not yet been elucidated.

In vitro experiments, ultra-low-molecular-weight heparin (ULMWH) partly reduced the $\left[\mathrm{Ca}^{2+}\right] \mathrm{i}$ increase induced by glutamate, this suggests that ULMWH may inhibit external $\mathrm{Ca}^{2+}$ influx mediated by NMDA receptor. In addition, the $\mathrm{IP}_{3} \mathrm{R}$ induced $\left[\mathrm{Ca}^{2+}\right]$ i was significantly suppressed ULMWH, suggests that ULMWH can regulate calcium balance by inhibiting calcium ion release. So ULMWH may be speculated as a specific $\mathrm{IP}_{3} \mathrm{R}$ antagonist just like heparin. In this way, less $\mathrm{IP}_{3}$ binds to $\mathrm{IP}_{3} \mathrm{Rs}$ and the increase of $\left[\mathrm{Ca}^{2+}\right] \mathrm{i}$ was blocked. Therefore, factors such as ULMWH are expected to have good effect on AD.

\section{Anti-Amyloid Therapies}

As $\mathrm{A} \beta$ is the heart of the amyloid hypothesis of $\mathrm{AD}$, the formation of $\mathrm{A} \beta$ oligomers is a directly $\mathrm{AD}$ killer. The mainly function of $\beta$-secretase and $\gamma$-secretase is to produce toxic $\mathrm{A} \beta_{1-42}$. Currently the focus of scientists is the inhibition of activity of $\beta$-secretase and $\gamma$-secretase. $\beta$-secretase (BACE1) initiates the amyloidogenic pathway. Activation of nuclear peroxisome proliferator-activated receptor $\gamma$ (PPAR $\gamma$ ) can suppress expression of $\beta$-secretase. Rosiglitazone and pioglitazone, which belong to oral drugs for type 2 diabetes, can act as $\beta$-secretase inhibitors by stimulating PPAR $\gamma$ [20]. The therapeutic effects of PPAR $\gamma$ agonists in AD may be caused by their effect of increasing insulin sensitivity and reducing concentrations of insulin.

Present study is generally believed that insulin can not only pass through the blood brain barrier, but also be synthesized within the brain tissue. The insulin receptor (IR) and receptor signal transduction molecules exist in brain tissue [21]. Insulin can not only regulate sugar metabolism and energy metabolism, but also have various biological functions. The function of brain insulin is complex, including supporting the surviving of mature neurons. Cascade control apoptosis is one of the important roles of insulin. The common pathological mechanism of diabetes encephalopathy and $\mathrm{AD}$ is an obstacle of insulin signal transduction pathways, namely the insulin resistance, which can cause metabolic disorders and cognitive dysfunction. In a word, insulin signaling induces the phosphorylation and inhibition of glycogen synthase kinase 3 (GSK3). It would therefore promote tau phosphorylation, leading to aggregation and tangle formation, as well as contributing to $\mathrm{A} \beta$ peptide production and plaque formation [22] (Figure 2). The related content remains further research.

Using $\mathrm{A} \beta$ antibody in treatment of $\mathrm{AD}$ is a current research hot spot. Active and passive immunization clinical research is ongoing in several pharmaceutical companies. According to animal tests, vaccination of synthetic $\mathrm{A} \beta_{1-42}$ immunization can produce $\mathrm{A} \beta_{1-42}$ antibody, thus causes activation of monocyte or microglia. As a result, immune therapy has become a new method for treatment of $\mathrm{AD}$, which has entered clinical trials in the United States. Preclinical and early clinical trial results show A $\beta$ immunotherapy has great potential to overcome the $\mathrm{AD}$. Active immunizations include injection of synthetic $\mathrm{A} \beta$ peptide, $\mathrm{A} \beta$ fragment joined with carrier protein or adjuvant. It will stimulate the host to produce antibodies against $\mathrm{A} \beta$. Passive immunization is to directly inject $\mathrm{A} \beta$ specific antibody into the host, thus activate the host immune system. The common basic principle of active and passive immunotherapy is removing $\mathrm{A} \beta$ from the brain. In clinical trials of AN-1792 vaccine, the number of $\mathrm{A} \beta$ has decreased in the brains of patients. However, some patients appeared subacute aseptic meningoencephalitis within II period clinical trials [23]. Better than AN-1792 vaccine, CAD-106 vaccine, did not show such side effect in the early human trials [24]. A new strategy to increase the security of active immunization is to optimize the drug delivery way. It has been proved that, intranasal administration of $\mathrm{A} \beta$ peptide, without adjuvant, 


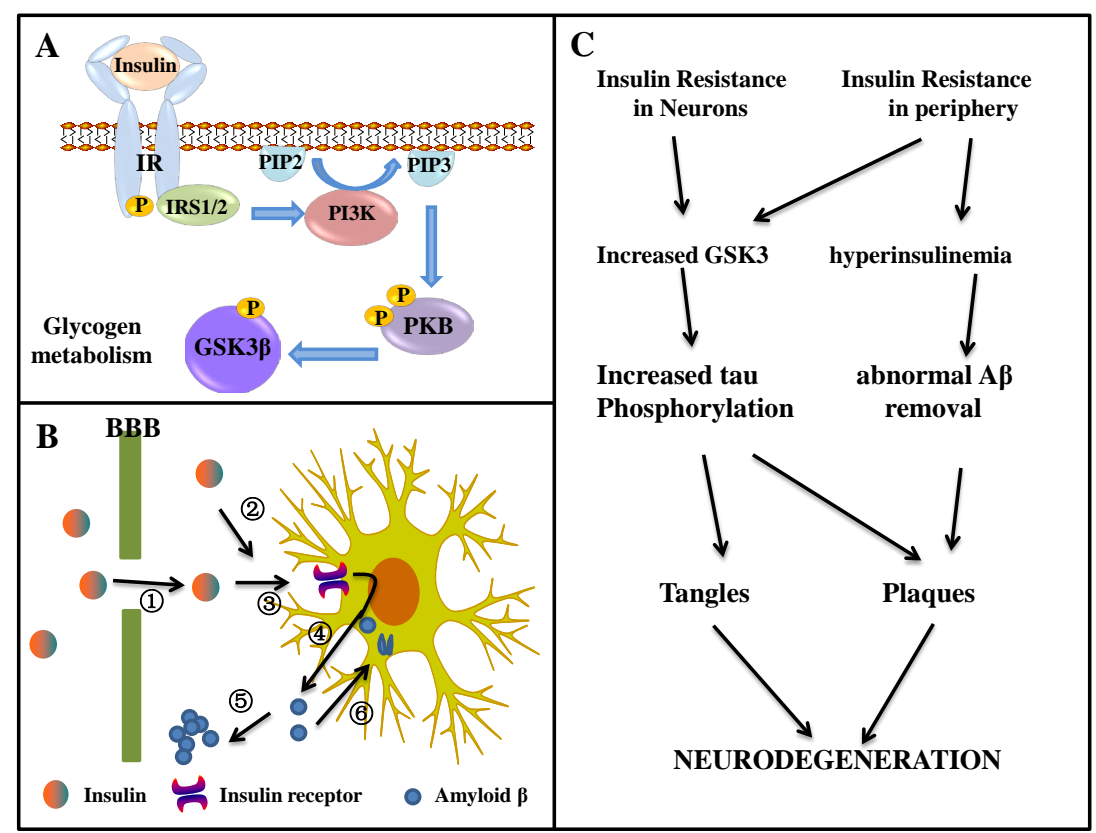

Figure 2. The role of insulin receptor (IR) in neurodegeneration, which is expressed in both neurons and glia. (A) Schematic representation of insulin signaling; (B) The potential role of insulin in the pathogenesis of $\mathrm{AD}$. Insulin is transported actively across the blood-brain barrier (1), it can also be produced locally in the brain (2). Insulin act through cerebral insulin receptors (3). Thus stimulates the secretion of $\mathrm{A} \beta$ into the extracellular space (4) where it can aggregate into senile plaques (5)). Alternatively, excessive $\mathrm{A} \beta$ can be cleared through endocytosis (6); (C) The connection between insulin resistance and neurodegeneration.

leads to appropriate immunoreaction. Gene immunotherapy, a kind of active immunization in essence, has much potential. Initially, $\mathrm{A} \beta$-DNA vaccine was coded by adenovirus or adeno-associated virus vector. Researchers are focusing on the development of non-viral plasmid vector, because of the large-scale low-cost production and no risk of infection or transfection [25].

As for passive immunization, many monoclonal antibody is in development and testing, such as Bapineuzumab (AAB-001) [26] and Solanezumab (LY2062430) [27] [28]. But the production of monoclonal antibodies cost great and need repeated injection. What's worse, it is hard to choose the appropriate target and pass through the BBB. It also has a risk of bleeding.

\section{Drugs to Target Tau Protein}

Tau protein is a kind of microtubule associated protein whose primary function is to stabilize the conformation of microtubules (MTs). The phosphorylation level of tau protein in AD patients' brain is three times higher than normal. Excessive phosphorylated tau protein may dissociate from microtubules and aggregates into nerve toxic NFTs [29]. As a consequence, microtubule is disintegrated and cytoskeleton is damaged, too.

There are two main therapeutic approaches aiming at tau protein: inhibitors of phosphorylase kinase of tau protein and compounds that inhibit tau aggregation or promote its disassembly. Inhibition of the excessive phosphorylation of tau protein is the major research direction for the treatment of AD. GSK3, and specifically its beta isoform (GSK3 $\beta$ ), have been shown to closely connected with phosphorylate tau [30]. Animal studies have confirmed that in the early pathological changes of tao protein, lithium salt, one kind of non-specific GSK3 inhibitor [31], can prevent excessive phosphorylation of tau protein and block the further progress of the disease. But lithium salt has little effect during the late stage, so researchers have turned to develop specific inhibitors of phosphorylase kinase of tau protein. According to the research results, some kind of small molecular compounds can prevent the interaction of tau protein, thus inhibit its aggregation. For example, methylene blue, a widely used histology dye, can not only prevent polymerization of tau protein into oligomers, but also reduce $\mathrm{A} \beta$ level 
in the brain [32]. Methylene blue also has antioxidant properties and was effective in improving learning deficits either used alone or in combination with rivastigmine in animals [33]. So it is considered to be a promising new $\mathrm{AD}$ treatment. It has a high bioavailability when tested in a phase 2 study in patients with moderate $\mathrm{AD}[34]$ and its safety and clinical efficacy need to be further confirmed.

In addition to the two kinds of medicine mentioned above, new drugs designed on counteracting the functional loss of tau protein are promising. As we all know, the primary function of tau protein is to stabilize the conformation of MTs. Over the past decades, several classes of MT-stabilizing products have been used as antineoplastic drug. However, people are worried about dose-limiting toxicities if this class of therapeutics is used in long-term treatment of tauopathy patients. Paclitaxel, which belongs to taxanes natural products, binds to the lumen of the MT at $\beta$-tubulin subunit [35]. Importantly, paclitaxel is found to having a function of promoting MT stabilization instead of tau protein. [36]. The actin mode of epothilones is similar to paclitaxel. In vitro, both paclitaxel [37]-[41] and epothilones [42]-[44] have been found to protect neurons against neurotoxicity mediated by tau protein or $\mathrm{A} \beta$. However, paclitaxel could not cross the BBB while epothilone $\mathrm{D}$ shows to be a brain-penetrant MT-stabilizing agent [45]. Considering that tau pathology is primarily in the brain, only epothilone D can be suitable as a therapeutic candidate for human tauopathies. As to the consideration of dose-limiting toxicities, one important observation made in vivo studies in epothilone D [46] indicated that low doses of epothilone D may produce optimal therapeutic effects. Overstabilization of MTs by high dose of agents on the other hand become counterproductive and may be accompanied by side effects. As a growing number of MT-stabilizing products are being discovered, a particular attention should be paid to these agents to find more useful treatment for $\mathrm{AD}$ and other tauopathies.

\section{Summary and Prospective}

The study of the pathophysiological processes of $\mathrm{AD}$ has been attracting people's attention for more than a century. $\mathrm{A} \beta$ and NFTs have been observed to have extensively damage to normal function of central nervous system, such as cholinergic deficit in the CNS, intracellular $\mathrm{Ca}^{2+}$ disequilibrium, inordinate oxidative stress and inflammatory processes. These pathophysiological processes of AD provide multifarious targets for therapeutic or preventative agents. Besides those five drugs which are currently ratified for use in the treatment of AD (donepezil $\left(\right.$ Aricept $\left.{ }^{\circledR}\right)$, galantamine $\left(\right.$ Reminyl $\left.{ }^{\circledR}\right)$, rivastigmine $\left(\right.$ Exelon $\left.^{\circledR}\right)$, tacrine $\left(\right.$ Cognex $\left.{ }^{\circledR}\right)$ and memantine (Namen$\left.\mathrm{da}^{\circledR}\right)$ ), many other kinds of drugs aiming at processes mentioned above have potentials in AD treatment, for example, GAG mimetic, NSAIDs, and hypoglycemic agents (Table 1).

According to the past failures we have met in AD drug clinical trials that were conducted over the last decades, we can come to the conclusion that it is questionable to conducting large clinical development programs in $\mathrm{AD}$ blindly. $\mathrm{AD}$ is the result of the interaction of pathogenic factors. It is necessary to be better appreciating the complicacy of the disease. In our way to find significant treatment for $\mathrm{AD}$, it is important to better understand the relationship between tau, $\mathrm{A} \beta$ and other factors. In a word, the competing risk factors, physiological factors such as age and genetics, and environmental factors all play non-ignorable roles in the progress of $\mathrm{AD}$. As a result, drugs with wide range of targets always appear little effect in the treatment.

The failures in $\mathrm{AD}$ drug clinical trials also forced people to turn to another approach to the treatment of AD. There are three kinds of behaviors that are considered to reduce the risk of $\mathrm{AD}$ [56]. Those are cognitive stimu-

Table 1. Different classes of products and their stages of development as potential candidates for AD.

\begin{tabular}{ccc}
\hline Main mechanisms of action & Candidate drugs & Stage of development in trails \\
\hline Acetylcholinesterase inhibitors & Huperzine A & RCTs completed [10] \\
Specific IP ${ }_{3}$ R antagonist & ULMWH & Vitro experiments [47] \\
$\beta$-secretase inhibitors & Rosiglitazone & RCTs completed [48] \\
& Pioglitazone & Phase 2 RCT in MCI [48] \\
& AN1792 and CAD-106 & RCTs completed [49] [50] \\
Active immunotherapy that increase A $\beta$ clearance & AAB-001 and LY2062430 & RCTs completed [51] [52] \\
Passive immunotherapy that increase A $\beta$ clearance & Lithium salt & RCTs completed [53] \\
Non-specific GSK3 inhibitor & Methylene blue & RCTs completed [54] \\
Anti-tau that decrease tau fibrillization & Paclitaxel & Vitro animal model [55] \\
MT-stabilizing products & Epothilone D & Phase 1b clinical trail [46] \\
&
\end{tabular}

RCT: Randomized Controlled Trial. MCI: Mild Cognitive Impairment. 
lation, mental and physical exercise, and dietary energy restriction. They are thought to show beneficial effect by activating neurotransmitters, growth factors, and hormone receptors. In this way, the synaptic activity in nerve cell networks is increased and neurons will be protected against oxidative and metabolic stress.

What's more, most compounds showed some benefits in mild AD, either than moderate AD. These discoveries inspire us that the early we carry out therapeutic trials, the more possible it will be to block the course of the disease. As a consequence, the identification of more accurate tools for early diagnosis is needed. If we have new markers that can detected in the blood or other body fluids at the mild phase of AD, it will be a useful aid for the diagnosis and management of patients with $\mathrm{AD}$.

\section{Acknowledgements}

The authors thank Dr. Li-Na Hao for her insightful advice, and Ms. Yu-Ning Song for her assistance in preparing the manuscript.

\section{References}

[1] Walsh, D.M. and Selkoe, D.J. (2004) Deciphering the Molecular Basis of Memory Failure in Alzheimer's Disease. Neuron, 44, 181-193. http://dx.doi.org/10.1016/j.neuron.2004.09.010

[2] Heneka, M.T. and O’Banion. M.K. (2007) Inflammatory Processes in Alzheimer's Disease. Journal of Neuroimmunology, 184, 69-91. http://dx.doi.org/10.1016/j.jneuroim.2006.11.017

[3] Lee, V.M., Goedert, M. and Trojanowski, J.Q. (2001) Neurodegenerative Tauopathies. Annual Review of Neuroscience, 24, 1121-1159. http://dx.doi.org/10.1146/annurev.neuro.24.1.1121

[4] Sue, W. and Griffin, T. (2006) Inflammation and Neurodegenerative Diseases. The American Journal of Clinical Nutrition, 83, 470S-474S.

[5] Jackson, S., Ham, R.J. and Wilkinson, D. (2004) The Safety and Tolerability of Donepezil in Patients with Alzheimer's Disease. British Journal of Clinical Pharmacology, 58, 1-8. http://dx.doi.org/10.1111/j.1365-2125.2004.01848.x

[6] Kumar, V., Anand, R., Messina, J., Hartman, R. and Veach, J. (2000) An Efficacy and Safety Analysis of Exelon ${ }^{\circledR}$ in Alzheimer's Disease Patients with Concurrent Vascular Risk Factors. European Journal of Neurology, 7, 159-169. http://dx.doi.org/10.1046/j.1468-1331.2000.00046.x

[7] Petersen, R.C., et al. (2005) Vitamin E and Donepezil for the Treatment of Mild Cognitive Impairment. New England Journal of Medicine, 352, 2379-2388. http://dx.doi.org/10.1056/NEJMoa050151

[8] Salloway, S., et al. (2004) Efficacy of Donepezil in Mild Cognitive Impairment A Randomized Placebo-Controlled Trial. Neurology, 63, 651-657. http://dx.doi.org/10.1212/01.WNL.0000134664.80320.92

[9] Corey-Bloom, J., Anand, R. and Veach, J.F. (1998) A Randomized Trial Evaluating the Efficacy and Safety of ENA 713(Rivastigmine Tartrate), a New Acetylcholinesterase Inhibitor, in Patients with Mild to Moderately Severe Alzheimer's Disease. International Journal of Geriatric Psychopharmacology, 1, 55-65.

[10] Bai, D. (2007) Development of Huperzine A and B for Treatment of Alzheimer's Disease. Pure and Applied Chemistry, 79, 469-479. http://dx.doi.org/10.1351/pac200779040469

[11] Camps, P., et al. (2008) Novel Donepezil-Based Inhibitors of Acetyl-And Butyrylcholinesterase and Acetylcholinesterase-Induced $\beta$-Amyloid Aggregation. Journal of Medicinal Chemistry, 51, 3588-3598. http://dx.doi.org/10.1021/jm8001313

[12] Sahu, S.K., Gummadi, S.N., Manoj, N. and Aradhyam, G.K. (2007) Phospholipid Scramblases: An Overview. Archives of Biochemistry and Biophysics, 462, 103-114. http://dx.doi.org/10.1016/j.abb.2007.04.002

[13] Simakova, O. and Arispe, N.J. (2007) The Cell-Selective Neurotoxicity of the Alzheimer's A $\beta$ Peptide Is Determined by Surface Phosphatidylserine and Cytosolic ATP Levels. Membrane Binding Is Required for A $\beta$ Toxicity. The Journal of Neuroscience, 27, 13719-13729. http://dx.doi.org/10.1523/JNEUROSCI.3006-07.2007

[14] Hensley, K., et al. (1994) A Model for Beta-Amyloid Aggregation and Neurotoxicity Based on Free Radical Generation by the Peptide: Relevance to Alzheimer Disease. Proceedings of the National Academy of Sciences, 91, 3270-3274. http://dx.doi.org/10.1073/pnas.91.8.3270

[15] Huang, X., et al. (1999) The A $\beta$ Peptide of Alzheimer's Disease Directly Produces Hydrogen Peroxide through Metal ion Reduction. Biochemistry, 38, 7609-7616. http://dx.doi.org/10.1021/bi990438f

[16] Dougherty, J.J., Wu, J. and Nichols, R.A. (2003) $\beta$-Amyloid Regulation of Presynaptic Nicotinic Receptors in Rat Hippocampus and Neocortex. The Journal of Neuroscience, 23, 6740-6747.

[17] Emre, M., Mecocci, P. and Stender, K. (2008) Pooled Analyses on Cognitive Effects of Memantine in Patients with Moderate to Severe Alzheimer's Disease. Journal of Alzheimer's Disease, 14, 193-199. 
[18] Fritze, J. and Walden, J. (1994) Clinical Findings with Nimodipine in Dementia: Test of the Calcium Hypothesis. Journal of Neural Transmission. Supplementum, 46, 439-453.

[19] Facchinetti, F., Fasolato, C., Giudice, E.D., Burgo, A., Furegato, S., et al. (2006) Nimodipine Selectively Stimulates $\beta$-Amyloid 1-42 Secretion by a Mechanism Independent of Calcium Influx Blockage. Neurobiology of Aging, 27, 218 227. http://dx.doi.org/10.1016/j.neurobiolaging.2005.02.006

[20] Landreth, G., Jiang, Q., Mandrekar, S. and Heneka, M. (2008) PPAR $\gamma$ Agonists as Therapeutics for the Treatment of Alzheimer's Disease. Neurotherapeutics, 5, 481-489. http://dx.doi.org/10.1016/j.nurt.2008.05.003

[21] Abbott, M.A., Wells, D.G. and Fallon, J.R. (1999) The Insulin Receptor Tyrosine Kinase Substrate p58/53 and the Insulin Receptor Are Components of CNS Synapses. The Journal of Neuroscience, 19, 7300-7308.

[22] Cole, A.R., Astell, A., Green, C. and Sutherland, C. (2007) Molecular Connexions between Dementia and Diabetes. Neuroscience \& Biobehavioral Reviews, 31, 1046-1063. http://dx.doi.org/10.1016/j.neubiorev.2007.04.004

[23] Orgogozo, J.M., Gilman, S., Dartigues, J.F., Laurent, B., Puel, M., et al. (2003) Subacute Meningoencephalitis in a Subset of Patients with AD after Abeta42 Immunization. Neurology, 61, 46-54. http://dx.doi.org/10.1212/01.WNL.0000073623.84147.A8

[24] Winblad, B.G., Minthon, L., Floesser, A., Imbert, G., Dumortier, T., et al. (2009) Results of the First-in-Man Study with the Active A $\beta$ Immunotherapy CAD106 in Alzheimer Patients. Alzheimer's \& Dementia, 5, P113-P114. http://dx.doi.org/10.1016/j.jalz.2009.05.356

[25] Rinne, J.O., Brooks, D.J., Rossor, M.N., Fox, N.C., Bullock, R., et al. (2010) ${ }^{11}$ C-PiB PET Assessment of Change in Fibrillar Amyloid- $\beta$ Load in Patients with Alzheimer's Disease Treated with Bapineuzumab: A Phase 2, Double-Blind, Placebo-Controlled, Ascending-Dose Study. The Lancet Neurology, 9, 363-372. http://dx.doi.org/10.1016/S1474-4422(10)70043-0

[26] Seubert, P., Barbour, R., Khan, K., Motter, R., Tang, P., et al. (2008) Antibody Capture of Soluble A $\beta$ Does Not Reduce Cortical A $\beta$ Amyloidosis in the PDAPP Mouse. Neurodegenerative Diseases, 5, 65-71. http://dx.doi.org/10.1159/000112834

[27] Siemers, E.R., Friedrich, S., Dean, R.A., Gonzales, C.R., Farlow, M.R., Paul, S.M. and DeMattos, R.B. (2010) Safety and Changes in Plasma and Cerebrospinal Fluid Amyloid [beta] after a Single Administration of an Amyloid [beta] Monoclonal Antibody in Subjects with Alzheimer Disease. Clinical Neuropharmacology, 33, 67-73. http://dx.doi.org/10.1097/WNF.0b013e3181cb577a

[28] DaSilva, K.A., Brown, M.E., and McLaurin, J. (2009) Reduced Oligomeric and Vascular Amyloid- $\beta$ Following Immunization of TgCRND8 Mice with an Alzheimer's DNA Vaccine. Vaccine, 27, 1365-1376. http://dx.doi.org/10.1016/j.vaccine.2008.12.044

[29] Himmler, A., Drechsel, D., Kirschner, M.W. and Martin, D.W. (1989) Tau Consists of a Set of Proteins with Repeated C-Terminal Microtubule-Binding Domains and Variable N-Terminal Domains. Molecular and Cellular Biology, 9, 1381-1388.

[30] Mangialasche, F., Solomon, A., Winblad, B., Mecocci, P. and Kivipelto, M. (2010) Alzheimer's Disease: Clinical Trials and Drug Development. The Lancet Neurology, 9, 702-716. http://dx.doi.org/10.1016/S1474-4422(10)70119-8

[31] Noble, W., Planel, E., Zehr, C., Olm, V., Meyerson, J., et al. (2005) Inhibition of Glycogen Synthase Kinase-3 by Lithium Correlates with Reduced Tauopathy and Degeneration in Vivo. Proceedings of the National Academy of Sciences of the United States of America, 102, 6990-6995. http://dx.doi.org/10.1073/pnas.0500466102

[32] Wischik, C.M., Edwards, P.C., Lai, R.Y., Roth, M. and Harrington, C.R. (1996) Selective Inhibition of Alzheimer Disease-Like Tau Aggregation by Phenothiazines. Proceedings of the National Academy of Sciences of the United States of America, 93, 11213-11218. http://dx.doi.org/10.1073/pnas.93.20.11213

[33] Deiana, S., Harrington, C.R., Wischik, C.M. and Riedel, G. (2009) Methylthioninium Chloride Reverses Cognitive Deficits Induced by Scopolamine: Comparison with Rivastigmine. Psychopharmacology, 202, 53-65. http://dx.doi.org/10.1007/s00213-008-1394-2

[34] Wischik, C. (2009) Rember: Issues in Design of a Phase 3 Disease Modifying Clinical Trial of Tau Aggregation Inhibitor Therapy in Alzheimer's Disease. Alzheimer's \& Dementia, 5, P74. http://dx.doi.org/10.1016/j.jalz.2009.05.175

[35] Nogales, E., Wolf, S.G., Khan, I.A., Ludueña, R.F. and Downing, K.H. (1995) Structure of Tubulin at $6.5 \AA$ and Location of the Taxol-Binding Site. Nature, 375, 424-427. http://www.nature.com/nature/journal/v375/n6530/pdf/375424a0.pdf

[36] Amos, L.A. and Löwe, J. (1999) How Taxol® Stabilises Microtubule Structure. Chemistry \& Biology, 6, R65-R69. http://dx.doi.org/10.1016/S1074-5521(99)89002-4

[37] Shemesh, O.A. and Spira, M.E. (2011) Rescue of Neurons from Undergoing Hallmark Tau-Induced Alzheimer’s Disease Cell Pathologies by the Antimitotic Drug Paclitaxel. Neurobiology of Disease, 43, 163-175. http://dx.doi.org/10.1016/j.nbd.2011.03.008

[38] Das, V. and Miller, J.H. (2012) Microtubule Stabilization by Peloruside A and Paclitaxel Rescues Degenerating Neu- 
rons from Okadaic Acid-Induced Tau Phosphorylation. European Journal of Neuroscience, 35, 1705-1717. http://dx.doi.org/10.1111/j.1460-9568.2012.08084.x

[39] Michaelis, M.L., Ranciat, N., Chen, Y., Bechtel, M., Ragan, R., et al. (1998) Protection against Beta-Amyloid Toxicity in Primary Neurons by Paclitaxel (Taxol). Journal of Neurochemistry, 70, 1623-1627. http://dx.doi.org/10.1046/j.1471-4159.1998.70041623.x

[40] Michaelis, M.L., Chen, Y., Hill, S., Reiff, E., Georg, G., Rice, A. and Audus, K. (2002) Amyloid Peptide Toxicity and Microtubule-Stabilizing Drugs. Journal of Molecular Neuroscience, 19, 101-105. http://dx.doi.org/10.1007/s12031-002-0018-2

[41] Michaelis, M.L., Ansar, S., Chen, Y., Reiff, E.R., Seyb, K.I., et al. (2005) $\beta$-Amyloid-Induced Neurodegeneration and Protection by Structurally Diverse Microtubule-Stabilizing Agents. Journal of Pharmacology and Experimental Therapeutics, 312, 659-668. http://dx.doi.org/10.1124/jpet.104.074450

[42] Brunden, K.R., Yao, Y., Potuzak, J.S., Ferrer, N.I., Ballatore, C., et al. (2011) The Characterization of MicrotubuleStabilizing Drugs as Possible Therapeutic Agents for Alzheimer's Disease and Related Tauopathies. Pharmacological Research, 63, 341-351. http://dx.doi.org/10.1016/j.phrs.2010.12.002

[43] Hoffmann, J., Fichtner, I., Lemm, M., Lienau, P., Hess-Stumpp, H., et al. (2009) Sagopilone Crosses the Blood-Brain Barrier in Vivo to Inhibit Brain Tumor Growth and Metastases. Neuro-Oncology, 11, 158-166. http://dx.doi.org/10.1215/15228517-2008-072

[44] O’Reilly, T., Wartmann, M., Brueggen, J., Allegrini, P.R., Floersheimer, A., Maira, M. and McSheehy, P.M. (2008) Pharmacokinetic Profile of the Microtubule Stabilizer Patupilone in Tumor-Bearing Rodents and Comparison of AntiCancer Activity with Other MTS in Vitro and in Vivo. Cancer Chemotherapy and Pharmacology, 62, 1045-1054. http://dx.doi.org/10.1007/s00280-008-0695-9

[45] Ballatore, C., Brunden, K.R., Huryn, D.M., Trojanowski, J.Q., Lee, V.M.Y. and Smith III, A.B. (2012) Microtubule Stabilizing Agents as Potential Treatment for Alzheimer's Disease and Related Neurodegenerative Tauopathies. Journal of Medicinal Chemistry, 55, 8979-8996. http://dx.doi.org/10.1021/jm301079z

[46] Barten, D.M., Fanara, P., Andorfer, C., Hoque, N., Wong, P.Y.A., et al. (2012) Hyperdynamic Microtubules, Cognitive Deficits, and Pathology Are Improved in Tau Transgenic Mice with Low Doses of the Microtubule-Stabilizing Agent BMS-241027. The Journal of Neuroscience, 32, 7137-7145. http://dx.doi.org/10.1523/JNEUROSCI.0188-12.2012

[47] Hao, L., Zhang, Q., Yu, T., Yu, L. and Cheng, Y. (2011) Modulation of Ultra-Low-Molecular-Weight Heparin on $\left[\mathrm{Ca}^{2+}\right] \mathrm{i}$ in Nervous Cells. Brain Research Bulletin, 86, 355-359. http://dx.doi.org/10.1016/j.brainresbull.2011.08.018

[48] Vellas, B., Sol, O., Snyder, P.J., Ousset, P.J., Haddad, R., et al. (2011) EHT0202 in Alzheimers Disease: A 3-Month, Randomized, Placebo-Controlled, Double-Blind Study. Current Alzheimer Research, 8, 203-212. http://dx.doi.org/10.2174/156720511795256053

[49] Mangialasche, F., Solomon, A., Winblad, B., Mecocci, P. and Kivipelto, M. (2010) Alzheimer’s Disease: Clinical Trials and Drug Development. The Lancet Neurology, 9, 702-716. http://dx.doi.org/10.1016/S1474-4422(10)70119-8

[50] Winblad, B., Andreasen, N., Minthon, L., Floesser, A., Imbert, G., et al. (2012) Safety, Tolerability, and Antibody Response of Active A $\beta$ Immunotherapy with CAD106 in Patients with Alzheimer’s Disease: Randomised, Double-Blind, Placebo-Controlled, First-in-Human Study. The Lancet Neurology, 11, 597-604. http://dx.doi.org/10.1016/S1474-4422(12)70140-0

[51] Scheltens, P., Sperling, R., Salloway, S. and Fox, N. (2012) Bapineuzumab IV Phase 3 Results. 5th Conference Clinical Trials on Alzheimer's Disease. The Journal of Nutrition, Health \& Aging, 16, 795-872.

[52] Doody, R. (2012) Safety and Efficacy of Solanezumab in Patient with Mild to Moderate Alzheimer's Disease: Results from Phase 3. 5th Conference Clinical Trials on Alzheimer's Disease. The Journal of Nutrition, Health \& Aging, 16, 801-802.

[53] Hampel, H., Ewers, M., Bürger, K., Annas, P., Mörtberg, A., et al. (2009) Lithium Trial in Alzheimer’s Disease: A Randomized, Single-Blind, Placebo-Controlled, Multicenter 10-Week Study. The Journal of Clinical Psychiatry, 70, 922-931. http://dx.doi.org/10.4088/JCP.08m04606

[54] Wischik, C.M., Bentham, P., Wischik, D.J. and Seng, K.M. (2008) O3-04-07: Tau Aggregation Inhibitor (TAI) Therapy with Rember ${ }^{\mathrm{TM}}$ Arrests Disease Progression in Mild and Moderate Alzheimer's Disease over 50 Weeks. Alzheimer's \& Dementia, 4, T167. http://dx.doi.org/10.1016/j.jalz.2008.05.438

[55] Zhang, B., Maiti, A., Shively, S., Lakhani, F., McDonald-Jones, G., et al. (2005) Microtubule-Binding Drugs Offset Tau Sequestration by Stabilizing Microtubules and Reversing Fast Axonal Transport Deficits in a Tauopathy Model. Proceedings of the National Academy of Sciences of the United States of America, 102, 227-231. http://dx.doi.org/10.1073/pnas.0406361102

[56] Texel, S.J. and Mattson, M.P. (2011) Impaired Adaptive Cellular Responses to Oxidative Stress and the Pathogenesis of Alzheimer's Disease. Antioxidants \& Redox Signaling, 14, 1519-1534. http://dx.doi.org/10.1089/ars.2010.3569 